\title{
C-H Functionalisation Through Singlet Chlorocarbenes Insertions - MP2 and DFT Investigations
}

\author{
M. Ramalingam ${ }^{1}$, K. Ramasami ${ }^{2}$, P. Venuvanalingam ${ }^{3}$, and V. Sethuraman ${ }^{1}$ \\ ${ }^{1}$ Rajah Serfoji Government College, Thanjavur-613005, India \\ ${ }^{2}$ Nehru Memorial College, Puthanampatti-621007, India \\ ${ }^{3}$ Bharathidasan University, Tiruchirapalli-620024, India
}

\begin{abstract}
The insertion reactions of singlet mono and dichlorocarbenes $\left({ }^{1} \mathrm{CHCl}\right.$ and ${ }^{1} \mathrm{CCl}_{2}$ ) into primary, secondary and tertiary $\mathrm{C}-\mathrm{H}$ bonds of methane, ethane, propane, $n$-butane and iso-butane have been investigated at ab initio (MP2) and DFT levels invoking 6-31g(d, p) basis set. Among the $\sigma$ and $\pi$ insertions into the said alkane $\mathrm{C}-\mathrm{H}$, both MP2 and DFT predict that the $\sigma$ approach is slightly favoured over the $\pi$ approach. For inverted $\sigma$ approach the barrier heights have been found to be $c a$. 2 to 5 times that of the normal $\sigma$ approach.
\end{abstract}

\section{Introduction}

The refrigerants hydrochloroflurocarbons (HCFCs) and hydroflurocarbons (HFCs) are not harmful to ozone layer as they are oxidized / photodissociated to halocarbenes [1]. The halocarbenes and carbenes are important transient intermediates in organic synthesis [2], in organometallic chemistry [3] and in gas phase combustion [4, 5]. In the ground state the singlet halocarbenes are stabilized over the triplet carbenes by a large $\sigma-\mathrm{p}_{\pi}$ separation $[6,7,8]$ and inductive/ mesomeric effects or a combination of both the effects. The vacant $\mathrm{p}_{\pi}$ and the occupied $\sigma$ orbitals make them electrophiles and nucleophiles respectively. The singlet carbenes follow the concerted one-step process through a three-center cyclic transition state [9] (Scheme 1). As the short lived transient carbenes can not be analysed easily by experimental methods,

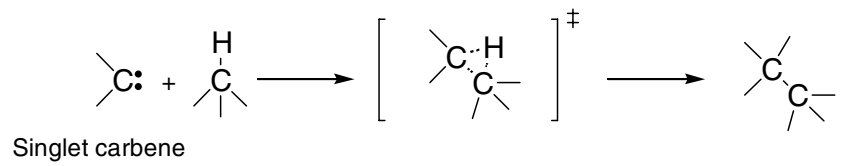

Scheme 1. Insertion pathway for singlet carbene

ab initio quantum mechanical method could be used as a powerful tool to investigate them. This is obvious from the fact that the activation barriers of 0 and $0.2 \mathrm{kcal} / \mathrm{mol}$ for ${ }^{1} \mathrm{CH}_{2}$ insertion into the $\mathrm{C}-\mathrm{H}$ of methane and ethane respectively at MP3/6-31g (d) [10-12] have been reported to be in excellent agreement with the experimental data $[2,13]$. But calculations at HF level overestimate the activation barrier heights due to 
lack of electron correlation [14-16]. In the halocarbenes, the halogens would interact with the carbenic carbon through the oppositely operating electronic [mesomeric $(+\mathrm{M})-\pi$ donor and inductive $(-\mathrm{I})-\sigma$ acceptor] effects. As a result of this the electrophilicity of the halocarbenes decreases with increased halogenation [8,17]. Consequently the activation barrier increases because the primary step in the carbene insertion is an electrophilic attack of the carbene center by the $\mathrm{C}-\mathrm{H}$ bond. This explains why the highly stable nucleophilic carbenes of Arduengo type [19] are completely unreactive towards the $\mathrm{C}-\mathrm{H}$ bonds. Hence nucleophilic carbene insertions are generally not observed at low temperature matrixes However certain intramolecular insertion of carbene into $\mathrm{C}-\mathrm{H}$ bond at $11 \mathrm{~K}$ has been observed [18]. Considering the chlorocarbenes $\left(\mathrm{CX}_{2}, \mathrm{X}=\mathrm{H}, \mathrm{Cl}\right)$ as electrophiles, two different pathways for the $\mathrm{C}-\mathrm{H}$ insertion process have been proposed according to FMO treatment $[20,21]$ (Scheme 2). In the $\pi$-approach the vacant $p_{\pi}$ orbital of chlorocarbene overlaps with the filled $\pi_{\mathrm{CH}_{2}}$ fragment orbital of alkane (1a). In the $\sigma$ approach the vacant $\mathrm{p}_{\pi}$ orbital of chlorocarbene overlaps with the $\sigma_{\mathrm{CH}_{2}}$ fragment orbital of the alkane (1b). The activation barrier of the reaction pathway is studied taking into account the orientation of the chlorocarbene and the electronic and steric effects. With due consideration of the electronic and steric factors, the present investigation focuses on the mechanism of ${ }^{1} \mathrm{CHCl}$ and ${ }^{1} \mathrm{CCl}_{2}$ insertion into the primary, secondary and the tertiary $\mathrm{C}-\mathrm{H}$ bonds of methane, ethane, propane, $\mathrm{n}$-butane and iso-butane (Scheme 3), as investigations of these have not been well documented.
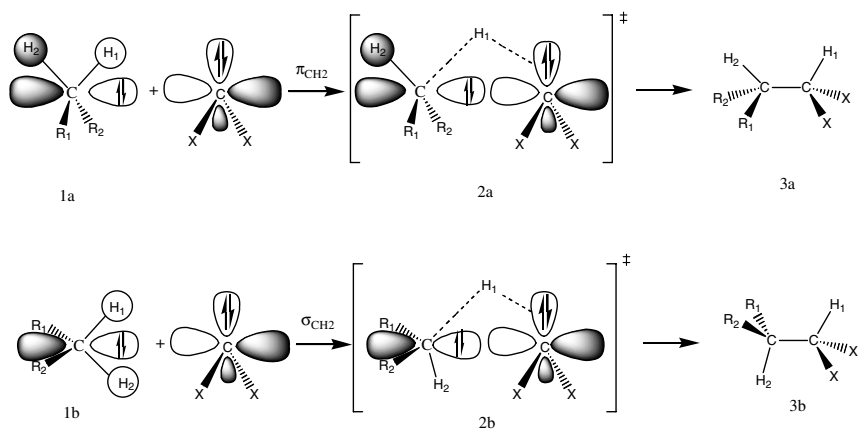

Scheme 2. The $\mathrm{pCH} 2$ and $\mathrm{sCH} 2$ orientations for the insertion of singlet carbenes

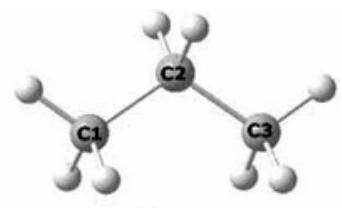

Propane

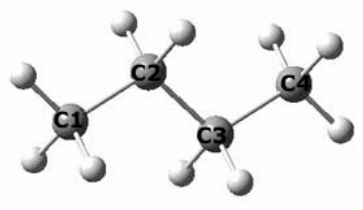

n-butane

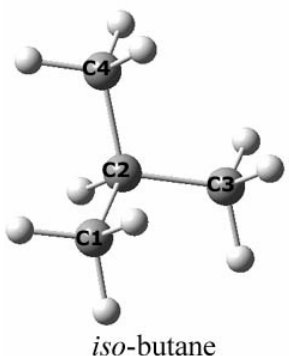

iso-butane

Scheme 3. Compounds and numbering system adopted in this study 


\section{Method of Calculations}

This investigation was performed with Gaussian03W suite of program [22] implemented on a Pentium IV/3.2 GHz processor. The geometries of the chlorocarbenes, the alkane substrates, the transition states and the products have been optimized initially at HF/6-31g (d, p) level. The resultant geometries were taken as inputs for MP2 and B3LYP [23-27], investigations. For a better treatment of 1, 2hydrogen shift during the insertion process, standard 6-31g (d, p) [28, 29] basis set has been adopted. In all the $\pi$-approaches the carbenic-carbon and the atoms of the CHR- unit of the alkane bearing the hydrogen that undergoes shift to the nucleophilic face of the carbene were constrained to be in one plane during the geometry optimization. The harmonic vibrational frequency calculations at MP2 and B3LYP levels were carried out to characterize all the stationary points as either minima, firstorder transition states or second-order saddle points - SOSP.

\section{Results and Discussion}

\subsection{Singlet Chlorocarbenes Insertion into Methane and Ethane}

The activation energies analysed in this investigation have been computed at B3LYP/6-31g (d, p) and MP2/6-31g (d, p) levels and all these have been listed in column 2 to 5 of Table 1 . The $\mathrm{p}_{\pi}$ of ${ }^{1} \mathrm{CHCl}$ and ${ }^{1} \mathrm{CCl}_{2}$ may interact with alkane's filled fragment orbital of either $\sigma$ or $\pi$ symmetry (Scheme 2). So chlorocarbenes insertion reactions have been investigated for both $(\sigma / \pi)$ the approaches and the $\sigma$ approach has been adjudicated to be the minimum energy path resulting in a staggered

Table 1. Activation barriers (in $\mathrm{kcal} / \mathrm{mol}$ ) for insertion of ${ }^{1} \mathrm{CHCl}$ and ${ }^{1} \mathrm{CCl}_{2}$ into alkanes at B3LYP/6-31G** and MP2/6-31G** levels for sigma (pi) orientations

\begin{tabular}{|c|c|c|c|c|}
\hline & \multicolumn{2}{|l|}{$\mathrm{CHCl}$} & \multicolumn{2}{|l|}{$\mathrm{CCl}_{2}$} \\
\hline & B3LYP & MP2 & B3LYP & MP2 \\
\hline methane & $4.87(5.15)$ & $7.05(7.35)$ & $20.57(21.44)$ & $18.83(19.83)$ \\
\hline $\begin{array}{r}\text { methane-sii } \\
\text { (methane-pii) }\end{array}$ & $23.59(19.58)$ & $22.87(20.12)$ & $43.65(39.91)$ & $38.28(38.28)$ \\
\hline ethane & $1.27(1.82)$ & $3.47(3.67)$ & $15.66(16.97)$ & $12.98(14.30)$ \\
\hline $\begin{array}{l}\text { ethane-sii } \\
\text { (ethane-pii) }\end{array}$ & $18.90(17.14)$ & $15.14(16.82)$ & $36.26(36.26)$ & $33.66(33.68)$ \\
\hline propane $(\mathrm{C} 1)$ & $1.37(1.80)$ & $3.22(3.35)$ & $15.90(17.38)$ & $12.60(14.17)$ \\
\hline propane $(\mathrm{C} 2)$ & $-0.64(0.50)$ & $0.79(1.39)$ & $12.45(13.80)$ & $8.59(10.24)$ \\
\hline n-butane $(\mathrm{C} 1)$ & $1.21(2.29)$ & $3.05(3.44)$ & $15.48(17.21)$ & $11.94(13.91)$ \\
\hline n-butane $(\mathrm{C} 2)$ & $-0.68(0.73)$ & $0.76(1.05)$ & $12.62(14.80)$ & $7.95(10.30)$ \\
\hline iso-butane $(\mathrm{C} 1)$ & $1.35(1.81)$ & $2.62(3.01)$ & $16.51(17.45)$ & $11.83(13.59)$ \\
\hline iso-butane (C2) & $-0.14(0.24)$ & -0.73 & $9.40(11.52)$ & $4.42(6.62)$ \\
\hline
\end{tabular}

sii - sigma inverted; pii - pi inverted. 
conformer. Our recent investigation of fluorocarbenes insertion [17] and the earlier report of carbene [30] and oxygen insertions [31] into $\mathrm{C}-\mathrm{H}$, also preferably assume $\sigma$ orientation over the $\pi$ approach. The $\sigma$ approaches of ${ }^{1} \mathrm{CHCl}$ and ${ }^{1} \mathrm{CCl}_{2}$ towards the $\mathrm{C}-\mathrm{H}$ of methane are associated with the activation energies of 4.87 and $20.57 \mathrm{kcal} / \mathrm{mol}$ respectively at B3LYP/6-31g (d, p) (Table 1). The MP2/6-31g (d, p) value for ${ }^{1} \mathrm{CHCl}$ insertion is ca. $2 \mathrm{kcal} / \mathrm{mol}$ higher and that for ${ }^{1} \mathrm{CCl}_{2}$ insertion is ca. 2 $\mathrm{kcal} / \mathrm{mol}$ lower than those of the corresponding B3LYP/6-31g (d, p) values. Replacement of hydrogen by chlorine in ${ }^{1} \mathrm{CHCl}$ decreases its electrophilicity [32]. So the barrier heights increase dramatically from 4.87 to $20.57 \mathrm{kcal} / \mathrm{mol}$ at B3LYP and 7.05 to $18.83 \mathrm{kcal} / \mathrm{mol}$ at MP2 calculations respectively for methane. Both in the $\sigma$ and the $\pi$ orientations the enhanced nucleophilicity of ethane seems to be the reason for the barrier height lowering through $\sim 3.3$ to $3.7 \mathrm{kcal} / \mathrm{mol}$ for ${ }^{1} \mathrm{CHCl}$ insertion. Similarly, the barrier height for ${ }^{1} \mathrm{CCl}_{2}$ into ethane does show the same trend (a reduction through $\sim 4.5$ to $5.9 \mathrm{kcal} / \mathrm{mol}$ ). This aspect is clear from the fact that the reactivity decreases as the chlorination increases in the carbene. An approximately two to five fold increase in activation barrier (at B3LYP and MP2 levels) for inverted $\sigma / \pi$ approach of ${ }^{1} \mathrm{CHCl} /{ }^{1} \mathrm{CCl}_{2}$ may be attributed to the fact that the migrating hydrogen approaches the smaller lobe of the $\sigma$ orbital of carbene carbon having the lone pair of electrons. Moreover the predominant $\pi$-donation over $\sigma$-attraction by chlorine atom could be the reason for this enormous increase in the activation barrier with the degree of chlorination.

Over all, the $\sigma_{\mathrm{CH}_{2}}$ orientation for ${ }^{1} \mathrm{CHCl}\left({ }^{1} \mathrm{CCl}_{2}\right)$ insertion has been found to be slightly preferred over the $\pi_{\mathrm{CH}_{2}}$ approach. The relevant geometrical parameters of the transition states for the ${ }^{1} \mathrm{CHCl}$ and ${ }^{1} \mathrm{CCl}_{2}$ insertions in $\sigma$ and $\pi$ orientations have been shown in Fig. 1. The TS for ${ }^{1} \mathrm{CCl}_{2}$ insertion (TS-2) comes much later along the reaction coordinate than that for ${ }^{1} \mathrm{CHCl}$ insertion (TS-1) as reflected in the relative C2-H1 bond distances of 1.430 (1.345) and 1.274 (1.202) $\AA$ and the charges on $\mathrm{H} 1$ of $0.284(0.260)$ and $0.253(0.225)$ respectively.

\subsection{Singlet Chlorocarbenes Insertion into C-H of Higher Alkanes}

The higher alkanes have three types of C-H bonds (primary, secondary and tertiary; Fig. 1) into which the carbenes can be inserted via the $\sigma / \pi$ approach. The B3LYP and MP2 barrier heights for these have been listed in Table 1. For the $\sigma$-insertion of ${ }^{1} \mathrm{CHCl}$ into primary $\mathrm{C}-\mathrm{H}$ of ethane to iso-butane, the barrier heights calculated at B3LYP/6-31g (d, p) have been found to be around $2.0 \mathrm{kcal} / \mathrm{mol}$. But MP2 predictions $(\sim 3.9 \mathrm{kcal} / \mathrm{mol})$ are slightly higher by $c a 1.9 \mathrm{kcal} / \mathrm{mol}$. The small reduction in barrier height on moving from methane to ethane $(3.5 \mathrm{kcal} / \mathrm{mol})$ should have been due to the enhanced nucleophilicity by the methyl substituent in methane and this effect is insignificant on further increasing the hydrocarbon chain length. The barrier heights were found to be negative for $\sigma$ approach at B3LYP/6-31g $(d, p)$ for the insertion at secondary and tertiary $\mathrm{C}-\mathrm{H}$ (Table 1$)$. But at MP2/6-31g(d, p) positive values have been observed, exception being the $\mathrm{C} 2$ of $i s o$-butane. The enhanced nucleophilicity of the substrate might be the reason for the negative barrier heights. 


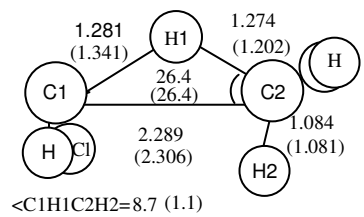

TS-1 $\left(\sigma_{\mathrm{CH} 2}\right)$

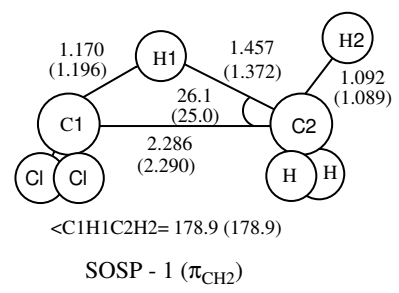

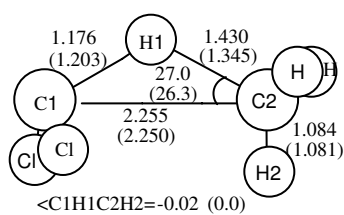

$\operatorname{TS}-2\left(\sigma_{\mathrm{CH} 2}\right)$

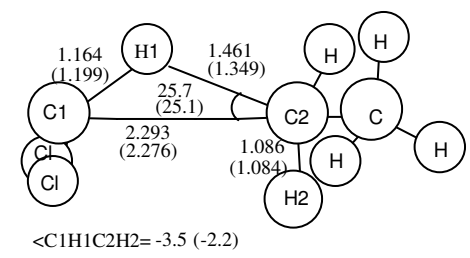

$\operatorname{TS}-3\left(\sigma_{\mathrm{CH} 2}\right)$

Fig. 1. Selected optimized geometrical parameters (distances in $\AA$ and angles in degrees) of the transition states at B3LYP/6-31g (d, p) and MP2/6-31g (d, p) (in parentheses) levels

If the carbene is ${ }^{1} \mathrm{CCl}_{2}$ the barrier height decreases to $\sim 16.8 \mathrm{kcal} / \mathrm{mol}$ at DFT for all primary $\mathrm{C}-\mathrm{H}$ insertions on comparison with that for methane and it falls around 13.7 $\mathrm{kcal} / \mathrm{mol}$ at MP2 level. The decreased electrophilicity may be the reason for the enhanced barrier heights. This trend also reveals that the steric factor has no noticeable influence upon the insertion pathway. For secondary $\mathrm{C}-\mathrm{H}$, the barrier heights have been found to be reduced to an average value of $c a .0 .78 \mathrm{kcal} / \mathrm{mol}$ and $8.27 \mathrm{kcal} / \mathrm{mol}$ for insertion of ${ }^{1} \mathrm{CHCl}$ and ${ }^{1} \mathrm{CCl}_{2}$ respectively at $\mathrm{MP} 2$ level. The proximity of the electron donating alkyl group to the insertion site might be the reason for this result. This is further supported by the lowered barrier heights for insertion of ${ }^{1} \mathrm{CHCl}$ or ${ }^{1} \mathrm{CCl}_{2}$ into the tertiary C-H of iso-butane both at B3LYP and MP2 levels.

\subsection{Energetics}

In the case of insertion of ${ }^{1} \mathrm{CHCl}$ and ${ }^{1} \mathrm{CCl}_{2}$ into an alkane, the order of the activation barrier is : tertiary $<$ seconday $<$ primary (Table 1 ). The above trend draws support from the fact that the pair of electrons on the carbene carbon involved in the bonding process is more and more stabilized with the degree of chlorination. Due to the less availability of the electron pair on the cabene carbon, ease of bond formation is inhibited. The NBO [33] analyses quantify this aspect in terms of the energies of the electron pairs on ${ }^{1} \mathrm{CHCl}$ and ${ }^{1} \mathrm{CCl}_{2}$ as -0.4057 and $-0.5595 \mathrm{au}$ at $\mathrm{B} 3 \mathrm{LYP}$ and -0.4535 and -0.6019 au at MP2 respectively.

The enthalpies of chlorocarbene insertion reactions calculated from the equation,

$$
\Delta_{\mathrm{r}} \mathrm{H}^{\mathrm{o}}(298 \mathrm{~K})=\Sigma\left(\varepsilon_{\mathrm{o}}+\mathrm{H}_{\text {corr }}\right)_{\text {products }}-\Sigma\left(\varepsilon_{\mathrm{o}}+\mathrm{H}_{\text {corr }}\right)_{\text {reactants }}
$$

$\varepsilon_{\mathrm{o}}$ - total electronic energy; $\mathrm{H}_{\text {corr }}$ - correction to the enthalpy due to internal energy have been listed in Table 2 . All the reaction enthalpies show the exothermicity of the insertion reactions indicating that all the transition states analyzed resemble the reactants rather than the products [34]. The proximity of the transition states to the 
reactants deviates with the degree of chlorination of carbene. HF/6-31g $(\mathrm{d}, \mathrm{p})$ calculations indicate an early transition state for the ${ }^{1} \mathrm{CH}_{2}$ with exothermicity around $-94 \mathrm{kcal} / \mathrm{mol}$ [17] compared to those formed by ${ }^{1} \mathrm{CHCl} /{ }^{1} \mathrm{CCl}_{2}$. Irrespective of the level of theory (B3LYP or MP2) followed, the insertions of ${ }^{1} \mathrm{CHCl}$ form the transition states earlier than those of ${ }^{1} \mathrm{CCl}_{2}$ insertions as revealed by exothermicity values (Table 2).

Table 2. Heat of reaction $(\mathrm{kcal} / \mathrm{mol})$ for insertion of singlet chlorocarbenes into $\mathrm{C}-\mathrm{H}$ bonds of alkanes using 6-31G(d,p) at B3LYP and MP2 levels

\begin{tabular}{rrrrrr}
\hline \multirow{2}{*}{ alkane } & \multicolumn{2}{l}{ CHCl } & & & $\mathrm{CCl}_{2}$ \\
\cline { 2 - 3 } \cline { 6 - 6 } & B3LYP & MP2 & & B3LYP & MP2 \\
\hline methane & -77.72 & -94.82 & & -62.92 & -78.25 \\
ethane & -79.31 & -97.63 & & -64.48 & -81.38 \\
propane (C1) & -79.14 & -97.66 & & -64.29 & -81.48 \\
propane (C2) & -79.83 & -99.75 & & -63.89 & -82.79 \\
n-butane(C1) & -79.14 & -97.73 & & -64.31 & -81.59 \\
n-butane(C2) & -78.73 & -99.09 & & -62.47 & -82.88 \\
iso-butane(C1) & -78.07 & -97.0 & & -63.41 & -78.54 \\
iso-butane(C2) & -79.25 & -101.1 & & -62.99 & -84.18 \\
\hline
\end{tabular}

\subsection{Transition State Geometries (NBO and IRC Analyses)}

The relevant computed data for all the transition states have been shown in Table 3 and Table 4. A scrutiny of the bond breaking and bond formation steps corresponding to $\mathrm{C} 2-\mathrm{H} 1$ and $\mathrm{C} 1-\mathrm{H} 1$ respectively during the insertion process reveals that it is a concerted reaction. It is observed that the maturity of $\mathrm{C} 1-\mathrm{H} 1$ bond takes place earlier than the $\mathrm{C} 1-\mathrm{C} 2$ bond in the TSs (Table 3 and Table 4). The C1-H1 distances are inversely related to the barrier heights as expected. A similar relationship is also obvious in the $\mathrm{C} 1-\mathrm{C} 2$ distances (Table 3 and Table 4). The $\mathrm{C} 2-\mathrm{H} 1$ distances in the bond breaking process in all the transition states for ${ }^{1} \mathrm{CHCl}$ insertions at $\mathrm{B} 3 \mathrm{LYP}$ (MP2)/6-31g $(\mathrm{d}, \mathrm{p})$ have been found to be $c a$. 1.264(1.197) $\AA$, 1.272(1.149) $\AA$ and $1.324(1.132) \AA$, respectively for primary, secondary and tertiary $\mathrm{C}-\mathrm{H}$ of higher alkanes. This shows again the belated transition states compared to that of ${ }^{1} \mathrm{CH}_{2}$ insertions [17]. The mean glide angle $\left(\theta_{\mathrm{H} 1 \mathrm{C} 2 \mathrm{Cl}}\right)$ decreases from primary to tertiary $\mathrm{C}-\mathrm{H}$ of the alkane (Table 3 ) and it gets reflected in the corresponding activation barriers (Table 1). Further correlation is also noticed when the torsion angles $\phi_{\mathrm{C} 1 \mathrm{H} 1 \mathrm{C} 2 \mathrm{H} 2}$ have been analyzed (Table 3 ). The quantum of charge transfer from alkane to carbene in TSs increases with the increase in the number of alkyl substituents on the $\mathrm{C} 2$ carbon (Table 3). It shows the inverse relationship between the barrier height and quantum of charge transfer. The same trend is observed in the case of ${ }^{1} \mathrm{CCl}_{2}$.

The NBO analyses of charge distribution in the transition state species give some insight into the insertion reactivity. They show that the $\sigma_{\mathrm{CH}} \rightarrow \mathrm{LP}^{*}$ interaction between the $\mathrm{C}-\mathrm{H}$ bond of alkane and $\mathrm{LP}^{*}$ of the carbene carbon seems to give the 
Table 3. Selected geometrical parameters (distances in $\AA$, angles in degrees, and barriers in $\mathrm{kcal} / \mathrm{mol})$ at the TSs of ${ }^{1} \mathrm{CHCl}$ with alkanes at B3LYP (MP2)/6-31g(d, p)

\begin{tabular}{rrrrrrrr}
\hline \multirow{2}{*}{ alkane } & $\mathrm{r}_{\mathrm{C} 1 \mathrm{H} 1}$ & $\mathrm{r}_{\mathrm{C} 1 \mathrm{C} 2}$ & $\mathrm{r}_{\mathrm{C} 2 \mathrm{H} 1}$ & $\theta_{\mathrm{H} 1 \mathrm{C} 1 \mathrm{C} 2}$ & $\theta_{\mathrm{H} 1 \mathrm{C} 2 \mathrm{C} 1}$ & $\Phi_{\mathrm{C} 1 \mathrm{H} 1 \mathrm{C} 2 \mathrm{H} 2}$ & \multicolumn{1}{c}{$\mathrm{q}_{\mathrm{ct}}$} \\
\hline \multirow{2}{*}{ methane } & 1.281 & 2.289 & 1.274 & 26.2 & 26.4 & 8.7 & 0.237 \\
& $(1.341)$ & $(2.306)$ & $(1.202)$ & $(23.5)$ & $(26.4)$ & $(1.1)$ & $(0.193)$ \\
ethane & 1.296 & 2.343 & 1.260 & 23.2 & 23.9 & 12.0 & 0.2527 \\
& $(1.409)$ & $(2.401)$ & $(1.173)$ & $(19.6)$ & $(23.8)$ & $(9.8)$ & $(0.161)$ \\
propane(c1) & 1.295 & 2.340 & 1.261 & 23.4 & 24.1 & 9.5 & 0.2531 \\
& $(1.416)$ & $(2.406)$ & $(1.172)$ & $(19.6)$ & $(23.9)$ & $(4.6)$ & $(0.157)$ \\
propane(c2) & 1.290 & 2.421 & 1.272 & 18.9 & 19.2 & 43.2 & 0.268 \\
& $(1.536)$ & $(2.545)$ & $(1.143)$ & $(15.6)$ & $(21.2)$ & $(5.3)$ & $(0.105)$ \\
n-butane(c1) & 1.296 & 2.342 & 1.261 & 23.3 & 24.0 & 8.7 & 0.253 \\
& $(1.422)$ & $(2.412)$ & $(1.170)$ & $(19.4)$ & $(23.8)$ & $(3.9)$ & $(0.154)$ \\
n-butane(c2) & 1.290 & 2.391 & 1.271 & 20.8 & 21.1 & 38.7 & 0.271 \\
& $(1.491)$ & $(2.521)$ & $(1.154)$ & $(15.5)$ & $(20.2)$ & $(31.9)$ & $(0.124)$ \\
isobutane(c1) & 1.289 & 2.334 & 1.266 & 23.8 & 24.3 & 10.0 & 0.259 \\
& $(1.425)$ & $(2.421)$ & $(1.168)$ & $(18.9)$ & $(23.4)$ & $(7.8)$ & $(0.152)$ \\
isobutane(c2) & 1.235 & 2.358 & 1.324 & 23.7 & 22.1 & 8.8 & 0.309 \\
& $(1.614)$ & $(2.690)$ & $(1.132)$ & $(9.7)$ & $(13.8)$ & $(18.4)$ & $(0.079)$ \\
\hline
\end{tabular}

$\mathrm{q}_{\mathrm{ct}}-$ quantum of charge transfer from alkane to carbene at the TSs.

Table 4. Selected geometrical parameters (distances in $\AA$, angles in degrees, and barriers in $\mathrm{kcal} / \mathrm{mol})$ at the TSs of ${ }^{1} \mathrm{CCl}_{2}$ with alkanes at B3LYP (MP2)/6-31g(d,p)

\begin{tabular}{crrrrrrr}
\hline alkane & $\mathrm{r}_{\mathrm{C} 1 \mathrm{H} 1}$ & \multicolumn{1}{c}{$\mathrm{r}_{\mathrm{C} 1 \mathrm{C} 2}$} & \multicolumn{1}{c}{$\mathrm{r}_{\mathrm{C} 2 \mathrm{H} 1}$} & $\theta_{\mathrm{H} 1 \mathrm{C} 1 \mathrm{C} 2}$ & $\theta_{\mathrm{H} 1 \mathrm{C} 2 \mathrm{C} 1}$ & $\Phi_{\mathrm{C} 1 \mathrm{H} 1 \mathrm{C} 2 \mathrm{H} 2}$ & \multicolumn{1}{c}{$\mathrm{q}_{\mathrm{ct}}$} \\
\hline \multirow{2}{*}{ methane } & 1.176 & 2.255 & 1.430 & 33.5 & 27.0 & 0.02 & 0.297 \\
& $(1.203)$ & $(2.250)$ & $(1.345)$ & $(29.7)$ & $(26.3)$ & $(0.0)$ & $(0.316)$ \\
ethane & 1.164 & 2.293 & 1.461 & 33.0 & 25.7 & -3.5 & 0.337 \\
& $(1.199)$ & $(2.276)$ & $(1.349)$ & $(28.5)$ & $(25.1)$ & $(2.2)$ & $(0.353)$ \\
n-propane(c1) & 1.164 & 2.291 & 1.461 & 33.1 & 25.8 & 0.7 & 0.336 \\
& $(1.201)$ & $(2.278)$ & $(1.348)$ & $(28.4)$ & $(25.1)$ & $(0.1)$ & $(0.352)$ \\
n-propane(c2) & 1.143 & 2.413 & 1.532 & 29.9 & 21.8 & 1.1 & 0.354 \\
& $(1.187)$ & $(2.379)$ & $(1.380)$ & $(23.9)$ & $(20.4)$ & $(3.3)$ & $(0.375)$ \\
n-butane(c1) & 1.163 & 2.295 & 1.470 & 33.3 & 25.8 & 4.0 & 0.342 \\
& $(1.199)$ & $(2.277)$ & $(1.350)$ & $(28.5)$ & $(25.1)$ & $(2.9)$ & $(0.361)$ \\
n-butane(c2) & 1.141 & 2.415 & 1.546 & 30.6 & 22.1 & 2.5 & 0.358 \\
& $(1.184)$ & $(2.375)$ & $(1.389)$ & $(24.6)$ & $(20.8)$ & $(3.9)$ & $(0.385)$ \\
isobutane(c1) & 1.163 & 2.291 & 1.462 & 33.1 & 25.7 & 0.2 & 0.348 \\
& $(1.199)$ & $(2.277)$ & $(1.350)$ & $(28.5)$ & $(25.1)$ & $(1.2)$ & $(0.357)$ \\
isobutane(c2) & 1.130 & 2.476 & 1.594 & 29.5 & 20.5 & 0.07 & 0.374 \\
& $(1.179)$ & $(2.401)$ & $(1.392)$ & $(22.8)$ & $(19.2)$ & $(0.01)$ & $(0.404)$ \\
\hline
\end{tabular}

$\mathrm{q}_{\mathrm{ct}-\mathrm{quantum}}$ of charge transferred from alkane to carbene at the TSs. 
strongest stabilization. Finally we observed that there was a net charge flow from the alkane unit to the inserting carbene moiety. The quantum of charge transfer from alkane to carbene supporting the donor-acceptor interaction in the transition states for all the insertion reactions have been collected in Tables 3 and 4. The inverse relationship between the quantum of charge transfer and the activation barriers reveals the fact that for the favorable insertion, the nucleophilicity of the alkane should have been enhanced either sterically or electronically. This correlation holds good for all the reactions analysed in this investigation. For example, in the case of ${ }^{1} \mathrm{CCl}_{2}$ insertion

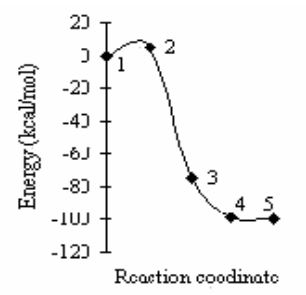

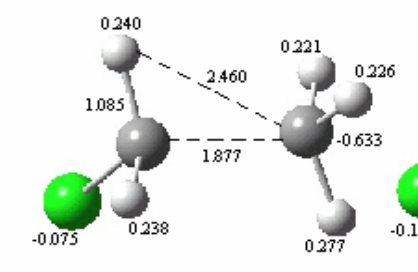

(3)

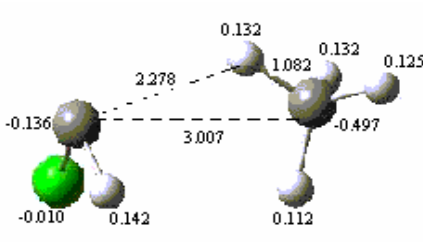

(1)

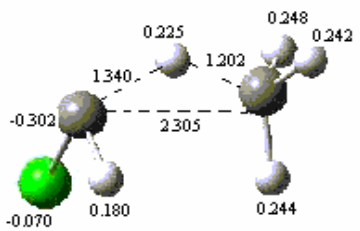

(2)

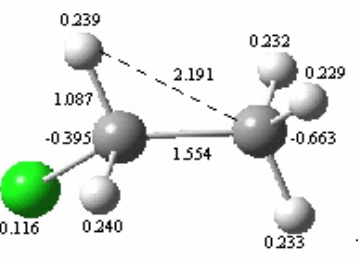

(4)

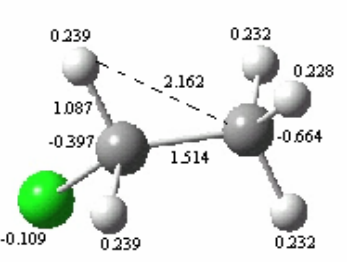

(5)

Fig. 2. IRC of insertion of ${ }^{1} \mathrm{CHCl}$ into $\mathrm{C}-\mathrm{H}$ bond of methane, calculated at $\mathrm{MP} 2 / 6-31 \mathrm{G}(\mathrm{d}, \mathrm{p})$
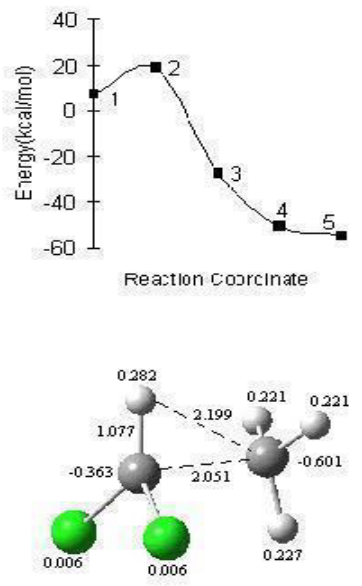

(3)

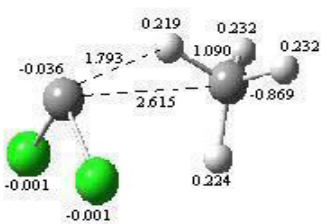

(1)

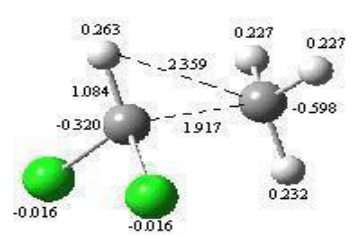

(4)

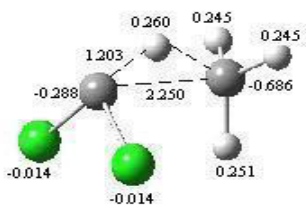

(2)

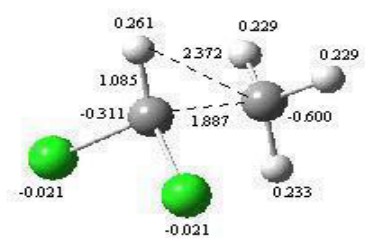

(5)

Fig. 3. IRC of insertion of ${ }^{1} \mathrm{CCl}_{2}$ into $\mathrm{C}-\mathrm{H}$ bond of methane, calculated at MP2/6-31G(d, p) 
into iso-butane at MP2 level the barrier heights, 11.83 and $4.42 \mathrm{kcal} / \mathrm{mol}$, for the primary and tertiary $\mathrm{C}-\mathrm{H}$ respectively correlate with the charge transfer of 0.357 and 0.404 .

The reaction path for the insertion of ${ }^{1} \mathrm{CHCl}$ into $\mathrm{C}-\mathrm{H}$ of methane has been studied by the IRC method at MP2 level (Fig. 2). In the transition state $\mathrm{C} 2-\mathrm{H} 1$ bond is elongated by $10.9 \%$. The stretching of the $\mathrm{C} 2-\mathrm{H} 1$ bond resulting in the $\mathrm{C} 1-\mathrm{H} 1$ bond formation and the charge transfer from the methane to chlorocarbene are closely linked together. Moreover the $\mathrm{C} 1-\mathrm{H} 1$ and the $\mathrm{C} 1-\mathrm{C} 2$ bond formations are found to be asynchronous.

The same trend is followed also in the case of ${ }^{1} \mathrm{CCl}_{2}$ (Fig. 3), the difference being that the less electrophilic character of ${ }^{1} \mathrm{CCl}_{2}$ compared to ${ }^{1} \mathrm{CHCl}$ results in a significantly reduced reactivity which is reflected in the higher activation barrier.

\section{Summary}

The singlet carbene insertion into the alkanes at the primary, secondary and tertiary C$\mathrm{H}$ bonds has been analyzed and the influence of chlorine on the transition states, energetics, geometrical parameters etc., has been investigated both at B3LYP and MP2 levels. Both the theories predict that the activation barrier is a function of the degree of chlorination of carbene and the type of $\mathrm{C}-\mathrm{H}$ into which insertion occurs. Also, among the two different types of carbene moiety approaches, i.e., $\sigma$ and $\pi$, the $\sigma$ approach is preferred over the $\pi$ approach at both levels of theory as the $\pi$ approach leads to the eclipsed conformation which is a second order saddle point. Intrinsic reaction coordinate analysis for the insertion in the case of ${ }^{1} \mathrm{CHCl}$ and ${ }^{1} \mathrm{CCl}_{2}$ into the primary $\mathrm{C}-\mathrm{H}$ of methane at MP2 has been carried out to show that the $\mathrm{C} 1-\mathrm{H} 1$ bond is formed first followed by the $\mathrm{C} 1-\mathrm{C} 2$ bond. The NBO analyses have been done with a view to analyzing the charge transfer processes during the insertion reactions.

\section{References}

1. Drake, S.A.,Standard, J.M., Quandt, R.W.: J. Phys. Chem.A. 106(2002) 1357

2. Kirmse, W.:Carbene Chemistry. 2nd Edn. Academic Press, New York (1971)

3. Fischer, E.O., Maasbol, A.: Angew. Chem., Int. Ed. Engl. 3 (1964) 580

4. Brahms, D.L.S., Dailey, W.P.: Chem. Rev. 96 (1996) 1585

5. Storer, J.W., Houk, K.N.:J.Am.Chem.Soc.115 (1993) 10426

6. Gleiter, R., and Hoffmann, R.: J. Am. Chem. Soc. 90 (1968) 1475

7. Irikura, K., Goddard III, W.A., Beauchamp, J.L.: J. Am. Chem. Soc. 114 (1992) 48

8. Russon, N., Siclia, E., Toscano, M.: J. Chem. Phys. 97 (1992) 5031

9. von W., Doering, E., Prinzbach, H.: Tetrahedron 6 (1959) 24

10. Bauchlicher, C., Bicher, W., Haber, K., Schaefer, H.F., Bender III, C.F.: J. Am. Chem. Soc. 99 (1977) 3610

11. Krishnan, R., Pople, J.A.: Int. J. Quantum Chem. Symp.14 (1980) 91

12. Gordon, M.S., Gano, D.R.: J. Am. Chem. Soc. 106 (1984) 5421

13. Jones, M., Moss, R.A.: Carbenes, Vol.1, Wiley, New York (1972)

14. Gordon, M.S., Boatz, J.A., Gano, D.R.: J. Am. Chem. Soc. 109 (1987) 1323

15. Gano, D.R., Gordon, M.S., Boatz, J.A.: J. Am. Chem. Soc. 113 (1991) 6711 
16. Gordon, M.S., Gano, D.R., Binkley, J.S., Frisch, M.J.: J. Am, Chem. Soc. 108 (1986) 2191

17. Ramalingam, M., Ramasami, K., Venuvanalingam, P., Sethuraman, V.: J. Mol. Struct.(Theochem) 755 (2005) 169

18. Zuev, P., Sheridan, R.S.: J. Am. Chem. Soc. 116 (1994) 4123

19. Arduengo, J., Goerlich, J.R., Krafezyk, R., Marshall, W.J.: Angew. Chem., Int. Ed., Engl. 37 (1998) 1963

20. Jorgensen, W.L., Salem, L.: The Organic Chemist's Book of Orbitals. Academic Press, New York (1973)

21. Meredith, C., Hamilton, T.P., Schaefer III, H.F.: J. Phys. Chem. 96 (1992) 9250

22. Gaussian 03, Revision C.02, Gaussian, Inc., Wallingford CT (2004)

23. Lee, C., Yang, W., Parr, R.G.: Physical Review B 37 (1988) 785

24. Becke, D.: Phys. Rev. A 38 (1988) 3098

25. Miehlich, B., Savin, A., Stoll, H., Preuss, H.: Chem. Phys. Lett. 157 (1989) 200

26. Becke, A.D.: J. Chem. Phys. 98 (1993) 5648

27. Becke, A.D.: J. Chem. Phys. 104 (1996) 1040

28. Franel, M.M., Pietro, W.J., Hehre, W.J., Bimcley, J.S., Gordon, M.S., DeFrees, D.J., Pople, J.A.: J. Chem. Phys., 77 (1982) 3654

29. Hariharan, P.C., Pople, J.A.: Chem. Phys. Lett. 66 (1972) 217

30. Bach, R.D., Su, M.D., Aldabbagh, E., Andres, J.L., Schlegel, H.B.: J. Am. Chem. Soc. 115 (1993) 10237

31. Bach, R.D., Andres, J.L., Su M.D., McDouall. J.J.W.: J. Am. Chem. Soc. 115 (1993) 5768

32. Gilles, M.K., Lineberger, W.C., Ervin, K.M.: J. Am. Chem. Soc. 115 (1993) 1031

33. Glendening, E.D., Reed, A.E., Carpenter, J.E., Weinhold, F., Curtiss, L.A.: Chem. Rev. 88 (1988) 899. NB Version 3.1

34. Carpenter, J.E.: Ph.D. Thesis, University of Wisconsin (Madison, WI) (1987) 